Thomas Hol Fosse, Assistant Professor, Norwegian Defence University College, Oslo; tfosse@mil.no

Robert Buch, Associate Professor, Department of Physical Education, Norwegian School of Sport Sciences; robert.buch@nih.no.

Reidar Säfvenbom, Associate Professor, Norwegian Defence University College, Norwegian School of Sport Sciences, Defence Institute; reidar.sefvenbom@nih.no

Monica Martinussen, Professor of Psychology, Norwegian Defence University College, Oslo and RKBU-Nord, UiT The Arctic University of Norway; monica.martinussen@uit.no

\title{
THE IMPACT OF PERSONALITY AND SELF- EFFICACY ON ACADEMIC AND MILITARY PERFORMANCE: THE MEDIATING ROLE OF SELF-EFFICACY
}

\begin{abstract}
In order to optimize recruitment and the overall outcome of educational programmes, it is crucial to understand personal determinants of achievement. While several cognitive abilities and skills individually predict performance in academic and professional settings, it is less clear how personality translates into performance. This study addresses the impact of the Big Five personality trait, conscientiousness, on academic performance and instructor performance ratings and examines the mediating role of selfefficacy. Analysis of longitudinal data (Time 1: $n=166$ (conscientiousness); Time 2: $n=161$ (self-efficacy); Time 3: $n=136$ (military performance) and $n=156$ (academic performance)) from three military academies in Norway showed that conscientiousness was related to both military and academic performance. Moreover, self-efficacy emerged as a partial mediator for the relationship between conscientiousness and performance.
\end{abstract}

Keywords

Big Five, personality traits, self-efficacy, military performance, academic performance 


\section{Introduction}

Identifying personal determinants of performance and success has always been a key challenge for the Armed Forces (Sellman, Born, Stricland, \& Ross, 2010). A considerable amount of resources are invested in the selection and training of military personnel. As work tasks become more specialized and technically demanding, the individual operative actions of soldiers are consistently gaining more strategic significance (Shamir, 2011). This accentuates the importance of valid selection processes and optimization of military education.

Several studies have identified personality traits and self-efficacy beliefs as predictors of both academic and work performance (Barrick, Mount, \& Judge, 2001; Judge, Ilies, Bono, \& Gerhardt, 2002; Judge, Jackson, Shaw, \& Rich, 2007; Poropat, 2009; Richardson, Abraham, \& Bond, 2012; Salgado, 1998). However, until now most studies have only examined such predictors independently. Caprara, Vecchione, Alessandri, Gerbino, and Barbaranelli (2011) pointed out that exaggerated focus on the differences between selfefficacy and personality traits might obstruct the integration of the two theories that address these factors. Personality traits and self-efficacy operate on different levels; i.e., personality traits may be regarded as describing the inherent character of a person (McCrae \& Costa, 1999) while self-efficacy describes how the person regulates his or her behaviour when interacting with the environment (Bandura, 1997). In this way, self-efficacy beliefs may allow inherent personality traits to be expressed as behaviour, suggesting a mediating function for self-efficacy. In relation to performance, conscientiousness is considered to be the strongest and most consistent predictor of the Big Five personality traits (Barrick et al., 2001; Caprara et al., 2011; Poropat, 2009). We, therefore, set out to test whether self-efficacy mediates the relationship between conscientiousness and performance in a military context. Recent studies support this mediation model when it comes to analysing academic performance at junior and senior high school levels (Caprara et al., 2011; Giunta et al., 2013) as well as certain aspects of work performance (Burns \& Christiansen, 2011). Our approach enabled us to test the model in a military setting and, more importantly, to address the simultaneous effect on two different performance criteria (military and academic). Additionally, this study answers the call for more research across 
professions (Burns \& Christiansen, 2011) while also including samples from various cultural contexts (Caprara et al., 2011).

\section{Personality traits and performance}

Personality traits may be used to describe individual differences in behavioural patterns and to provide a suitable means of studying daily behaviour and performance across a wide range of domains (Feyter, Caers, Vigna, \& Berings, 2012; Poropat, 2009). The Big Five consists of five broad dimensions typically referred to as extraversion, agreeableness, conscientiousness, neuroticism and openness to new experiences (McCrae \& Costa, 1999). Individuals scoring high on the trait, conscientiousness, are characterised as being well-organised and goal-oriented while also exhibiting high levels of self-discipline (McCrae \& Costa, 1986). In a meta-analysis of the correlations between the Big Five traits and academic performance, conscientiousness was found to be the strongest predictor for academic performance among the five dimensions (mean $r=.19$ ), and only slightly less predictive than intelligence measures (mean $r=.23$ ) (Poropat, 2009). This meta-analysis was based on 80 studies including more than 70,000 students. A meta-analysis of the relationship between Big Five and work performance has shown that conscientiousness is a valid predictor of performance across all types of occupations studied (Barrick et al., 2001). This is in line with earlier meta-analyses on civilian and military occupations (Barrick \& Mount, 1991; Salgado, 1998; Tett, Jackson, \& Rothstein, 1991). A meta-analysis based on 73 studies found a mean correlation between conscientiousness and leader efficiency of $r=.38$ (Judge et al., 2002).

The other Big Five traits have demonstrated smaller or no correlation with academic and work performance (Martin, Montgomery, \& Saphian, 2006; Poropat, 2009) with the exception of some aspects of work performance in selected occupations (Barrick et al., 2001). Extroversion is the trait with the strongest correlation to leader efficiency (mean $r=.31$ ), while openness has a moderate and positive correlation $(r=.24)$ to leader efficiency (Judge et al., 2002). 


\section{Self-efficacy and performance}

Self-efficacy refers to an individual's perceived capability to perform in a way that creates control over events affecting his/her life (Bandura, 1999). Individuals with higher self-efficacy have confidence in their ability to overcome obstacles and to perform well (Bandura, 1997). Self-efficacy regulates the way that humans function through cognitive, motivational, emotional and decisive processes (Bandura \& Locke, 2003). According to social cognitive theory, self-efficacy arises from four main sources: mastery experiences, observational learning, social persuasion and emotional arousal (Bandura, 1994). A meta-analysis of performance in a university environment showed that performance self-efficacy was the strongest predictor (performance self-efficacy $r=.59, N=1,348$ ) of 50 different variables predicting the grade point average (GPA) of students, while academic self-efficacy had a medium correlation to academic performance ( $r$ $=.31, N=46,570$ ) (Richardson et al., 2012). Conclusions are in line with earlier meta-analyses of the relationship between self-efficacy and performance (Multon, Brown, \& Lent, 1991; Robbins et al., 2004). Stajkovic and Luthans (1998) examined the relationship between self-efficacy and work performance in a meta-analysis of 114 studies $(N=21,616)$, finding a significant mean correlation of .38 . However, this relation was moderated by task complexity, whereby the correlation was strongest for simple tasks (Stajkovic \& Luthans, 1998).

\section{Personality traits, self-efficacy and performance}

Conscientiousness and self-efficacy beliefs can be decisive personal determinants of academic and work performance, however, they address distinctive structures and processes while also operating on different levels (Caprara et al., 2011). Personality traits describe the inherent character and potential of a person (McCrae \& Costa, 1999) whereas self-efficacy develops through perceived ability, feedback and reflection, which then regulate behaviour accordingly (Bandura, 1997). In this manner, self-efficacy beliefs may allow inherent personality traits to develop into behaviour.

Studies have indicated that the relationship between conscientiousness and performance may be mediated by self-efficacy beliefs. A recent study found 
that academic self-efficacy completely mediated the effect of conscientiousness on senior high school grades (Giunta et al., 2013), while an earlier study reported only partial mediation of self-efficacy for the relationship between conscientiousness and academic performance (Caprara et al., 2011; Tabak, Nguyen, Basuray, \& Darrow, 2009). The findings have varied in relation to how conscientiousness influences work performance, ranging from full mediation to partial mediation and no mediation at all (Caprara, Barbaranelli, Borgogni, \& Perugini, 1993).

There is no single answer to how this mediation occurs. Some theorists refer to the way in which conscientiousness affects motivation, thereby influencing the level of effort and stamina one chooses to expend (Tabak et al., 2009). Illustrating this, Judge and Ilies (2002) showed that conscientiousness correlated positively to three types of motivation to perform: goal-setting, expectancy and self-efficacy. Motivation, as such, may represent a possible explanation for how self-efficacy leads to improved performance by influencing interest, persistence, goals and learning strategies (Dinther, Dochy, \& Segers, 2011). Individuals scoring high on conscientiousness have a tendency to get more involved and to work harder towards their goals. This, in turn, contributes to an increased sense of accomplishment, greater verbal support from others and increased control over negative emotions (Bandura, 1994), thereby allowing such individuals to achieve a higher level of self-efficacy and a potentially better performance. This train of thought is in line with Mischel and Shoda (1998) who found that conscientiousness is involved in activating expectations of self-efficacy. Furthermore, Martocchio and Judge (1997) concluded that self-efficacy represents the mechanism through which general tendencies towards conscientiousness manifest themselves.

Military education at Norway's Army War College, Air War College and Sea War College consists of theoretical lectures and practical training and exercises. Instructors evaluate cadets on both academic achievement and ability to execute the training. Military performance thus involves both leadership skills and other types of work proficiency. When considering the context of military education, we therefore expect that self-efficacy mediates the relationships between conscientiousness and military performance and 
conscientiousness and academic performance. In other words, we predict that the relationship between conscientiousness and performance may be explained by the way in which each of them relates to self-efficacy.

Based on existing literature and theoretical assumptions, the following hypotheses are proposed:

Hypothesis 1: Self-efficacy mediates the relationship between conscientiousness and academic performance Hypotheses 2: Self-efficacy mediates the relationship between conscientiousness and military performance.

\section{Method}

\section{Participants}

Data for this study was collected from cadets attending three Norwegian military academies between 2007 and 2011. Participation at each measurement interval was 166 respondents at $T_{1}, 161$ respondents at $T_{2}$. At $\mathrm{T}_{3}$ we collected 156 academic grades and 136 instructors ratings based on additional consent. At the initial sample at $\mathrm{T}_{1}$ comprised $87.9 \%$ men and $12.1 \%$ women, with a mean age of $25.4(S D=3.51)$. All participants had previous military experience, with the most frequent rank being that of midshipman. In terms of age, military experience and rank, Norwegian military academy students are widely comparable to those of other NATO countries (Johansen, Laberg, \& Martinussen, 2013). This study was part of a larger project examining physical health and individual differences among students attending military academies in Norway.

\section{Measures}

The study questionnaire included several scales in addition to demographic variables such as level of prior civilian education, age, school affiliation (Air, Army and Navy), and gender. Civil education was coded 1= lower secondary school, 2 = upper secondary school, $3=1-3$ years of college or university, and $4=$ more than 4 years of college or university.

Big Five Inventory. The Big Five personality dimensions were measured using the Big Five Inventory (Engvik \& Føllesdal, 2005). The Norwegian 
version of the inventory consists of 44 statements, and was based on the Big Five Inventory of John and Srivastava (1999). Each statement was answered on a 7 -point Likert scale ( $1=$ strongly disagree to $7=$ strongly agree). Some items were negatively formulated and were reversed before the scale score was computed. Sample items include the following: "doing a thorough job" (conscientiousness), "curious about many things" (intellect/openness), "unselfish and willing to help others" (agreeableness), "worried a lot" (emotional stability) and "can be shy and inhabit" (extroversion). The internal consistency (Crohnbach's alfa) was calculated for each dimension with the following results: conscientiousness $(\alpha=.77)$, extroversion $(\alpha=.84)$, openness to experience $(\alpha=.75)$, emotional stability $(\alpha=.78)$, and agreeableness $(\alpha=.72)$.

Self-efficacy. In order to measure self-efficacy in a military context a 7-item scale was used (Buch, Säfvenbom, \& Boe, 2015). Sample items include "will manage to complete the military training" and "will achieve a result I can be proud of". The respondents indicated their responses on a 7-point scale ( $1=$ totally disagree to $7=$ totally agree). The scale had an internal consistency of $\alpha=.83$.

Academic performance. Academic performance was assessed through academic grades. The study programme is composed of multiple courses that represent 60 ECTS-credit points for each of the three years. Grades are issued from A to F, where F signifies fail. The cadets took exams in subjects like military leadership, strategy and English. We used the average grades from $\mathrm{T} 3$ as a performance indicator. The grades were transformed into numbers from 1 to 6 , where the highest number represents the best grade (A).

Military performance. Military performance was assessed by using instructors' ratings in the standard officer evaluation scale of the Norwegian Armed Forces. The military performance score is awarded at one time point only. The candidates are evaluated at the end of the last year of training. While the score emphasizes the overall impression of the candidate at the point of evaluation, it will also take into account the cadet's development throughout the three years. The evaluation is written and approved by three different instructors. The scale, which has been used in prior research 
(Johansen et al., 2013), consists of 10 items covering the following domains: general leadership, responsibility, cooperation/communication, technical skills, judgment, writing skills, orals skills, creativity, coping, and perspective. Officers in command evaluate their cadets on a 5-point Likerttype scale (below average, slightly below average, average, slightly above average and above average). The average score across all ten domains was used for the analysis. The scale had an internal consistency of $\alpha=.91$.

\section{Procedure}

$\mathrm{T}_{1}$ data (personality traits) was collected at the end of the second academic year. $T_{2}$ data (self-efficacy) was gathered towards the end of the cadets' third year (spring) and $\mathrm{T}_{3}$ data (performance) was collected after completion of the final academic year (summer). The questionnaires were distributed at school and completed in plenary with a member of the research team on site. Questions included topics covering individual differences, training and health. Respondents were informed that Norwegian Social Science Data Services had approved the survey and were assured of its strict confidentiality. In addition, respondents were assured that the results were to be used solely for research purposes and not for future selection.

\section{Statistical analysis}

To examine whether the items reflected the construct they were intended to measure, we performed a confirmatory factor analysis (CFA) as implemented in Mplus 7.3. Because ordinal variables "are not continuous and should not be treated as if they are" Jöreskog $(2005$, p. 10) the weighted least squares (WLSMV) estimator was used (Muthén, du Toit, \& Spisic, 1997) to accommodate the ordered categorical data (e.g. Flora \& Curran, 2004). Since the cadets were clustered within different institutions such as the Navy, Air Force, and Army academies the observations in the dataset are not independent. Accordingly, to account for the nested nature of the data we estimated the CFA model using cluster robust standard errors (at the academy level). To test whether self-efficacy mediates the relationship between conscientiousness and performance, we followed a similar procedure as Kuvaas, Buch, and Dysvik (2014) and estimated a structural equation model (SEM) using the delta method procedure in Mplus (using the 
Sobel test with cluster robust standard errors). According to Zhao, Lynch, and Chen (2010) the SEM approach is superior to the mediation approach of Baron and Kenny (1986) because it estimates everything simultaneously rather than assuming independent equations. Furthermore, the Baron and Kenny approach is among the lowest in power and does not provide a quantification of the indirect effect (Fritz \& MacKinnon, 2007). Due to the fact that prior civilian education could influence the cadets' academic selfefficacy beliefs, level of prior civilian education was entered as a control variable (Bandura, 1997). Age and gender may also be related to personality and self-efficacy (Bandura, 1997; Caprara et al., 2011) and was, therefore, entered as control variables in order to rule out alternative explanations for observed findings. For the same reason school affiliation, represented by two dummy variables (Bandura, 1997; Caprara et al., 2011) were introduced as control variables.

\section{Results}

The results of a six-factor CFA model that represented conscientiousness, extraversion, agreeableness, openness/intellect, emotional stability and selfefficacy indicated acceptable fit with the data $\left(\chi^{2}[1549]=2399.43, p<0.01\right.$; RMSEA $=0.059$ (90 \% CI: $0.055-0.064) ; \mathrm{CFI}=.87)$. Specifically, although the chi square test of exact fit was unsatisfactory $\left(\chi^{2}[1209]=1955.54, p<\right.$ .001 ), and the CFI was below the desired threshold of .90 (Hu and Bentler, 1999), the RMSEA test of close fit was well below the threshold of .08 $($ RMSEA $=.057 ; 90 \%$ CI: .053 - .062)(e.g. Hair, Black, Babin, Anderson, \& Tatham, 2005). Furthermore, Kenny and McCoach (2003) noted that the CFI "tend to worsen as the number of variables in the model increases" (p. 333), and further that "It would be most unfortunate to penalize researchers for estimating elaborate, theoretically interesting models with many variables" (p. 350). Hence, in view of the fact that our CFA model included six factors with more than fifty indicators we regarded the model fit as satisfactory. Table 1 reports means, standard deviations and Pearson's correlation among the study variables. As expected, conscientiousness at $\mathrm{T}_{1}$ was positively related to self-efficacy $(r=.48, p<.01)$ at $\mathrm{T}_{2}$, and to academic performance $(r=.27, p<.01)$ and military performance $(r=.39, p<.01)$ at $\mathrm{T}_{3}$. 
Table 1. Descriptive Statistics and Correlations for Study Variables

\begin{tabular}{|c|c|c|c|c|c|c|c|c|c|c|}
\hline Variables & $M$ & $S D$ & 1 & 2 & 3 & 5 & 6 & 7 & 9 & 10 \\
\hline \multicolumn{11}{|l|}{ Control variables } \\
\hline 1 Sex & - & - & & & & & & & & \\
\hline 2 Age & 25.43 & 3.51 & -.12 & & & & & & & \\
\hline 3 Civil education & 2.80 & 1.00 & .05 & $-.42 * *$ & & & & & & \\
\hline \multicolumn{11}{|l|}{ Predictor variables } \\
\hline 4 Conscientiousness & 4.98 & .75 & -.02 & .00 & -.00 & $(.77)$ & & & & \\
\hline 5 Emotional stability & 5.27 & .76 & $-.28 * *$ & .02 & -.04 & $.41 * *(.78)$ & & & & \\
\hline 6 Openness to experience & 4.48 & .79 & .03 & $.18^{*}$ & -.08 & $\begin{array}{ll}.07 & -.09\end{array}$ & $(.75)$ & & & \\
\hline 7 Agreeableness & 5.06 & .69 & -.00 & .01 & .03 & $.28 * * .31 * *$ & -.06 & $(.72)$ & & \\
\hline 8 Extraversion & 4.74 & .90 & -.06 & .04 & .02 & $.16^{*} .34^{* *}$ & $.19^{*}$ & .07 & $(.84)$ & \\
\hline 9 Self-Efficacy & 5.88 & .88 & -.16 & .02 & -.10 & $.48 * * .31 * *$ & .09 & .08 & $.21 *(.83)$ & \\
\hline \multicolumn{11}{|l|}{ Outcome variables } \\
\hline 10 Academic performance & 3.68 & .59 & $-.24 * *$ & $.25 * *$ & .15 & $.27 * * .15$ & .06 & -.14 & $.06 \quad .45^{* *}$ & \\
\hline 11 Military performance & 3.77 & .80 & -.11 & $.19^{*}$ & -.09 & $.39 * * \quad .11$ & .09 & -.01 & $.04 \quad .59 * *$ & $.65 * *(.91)$ \\
\hline
\end{tabular}
Note: $n=166$ (conscientiousness T1), $n=161$ (self-efficacy T2), $n=136$ and 156 (military and academic performance T3, respectively).

$* p<.05{ }^{* *} p<.01$ (two-tailed). Sex was coded $0=$ male $1=$ female. Coefficient alphas are displayed on the diagonal. 


\section{Mediation}

We hypothesized that self-efficacy mediated the relationships between conscientiousness and academic performance, and between conscientiousness and military performance. The results of the structural equation model $\left(\chi^{2}[1549]=2399.43, p<0.01\right.$; RMSEA $=0.059(90 \% \mathrm{CI}$ : $0.055-0.064$; CFI $=.82)$ presented in Table 2 show that conscientiousness at $\mathrm{T}_{1}$ was positively and significantly related to self-efficacy $(\gamma=.50, p<.001)$ measured at $\mathrm{T}_{2}$, and that self-efficacy measured at $\mathrm{T}_{2}$ was positively related to both academic performance $(\gamma=.41, p<.001)$ and military performance $(\gamma$ $=.60, p<.001)$ measured at $\mathrm{T}_{3}$. Furthermore, the results demonstrated positive and significant indirect relationships from conscientiousness at $\mathrm{T}_{1}$ to academic performance (standardized effect $=.20, p<.001$ ), and military performance (standardized effect $=.30, p<.001$ ) at $\mathrm{T}_{3}$ via self-efficacy at $\mathrm{T}_{2}$.

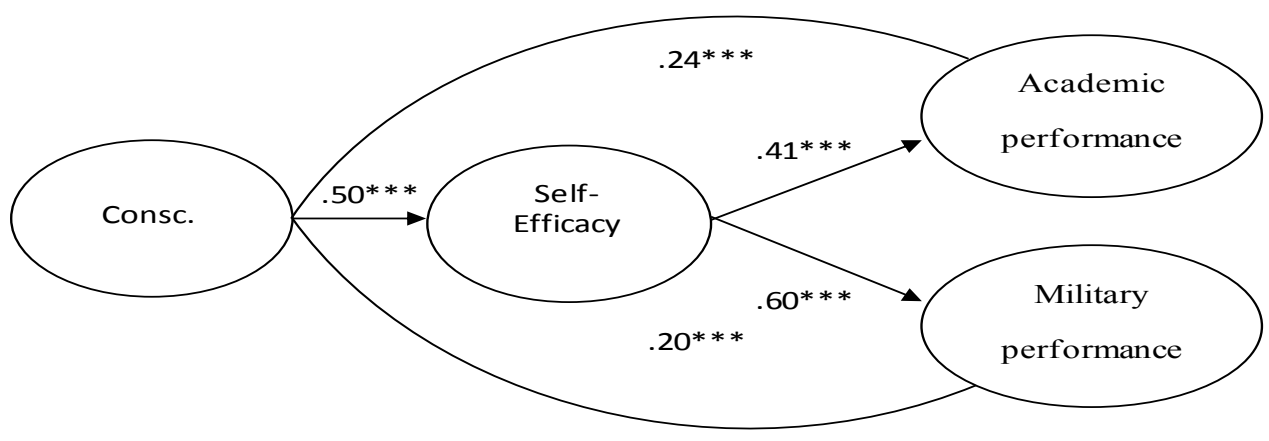

Note. $n=166$ (conscientiousness T1), $n=161$ (self-efficacy T2), $n=136$ and 156 (military and academic performance T3, respectively).

$* p<.05,{ }^{*} p<.01, p * * *<.001$. Sex was coded $0=$ male $1=$ female. Fit indices: $\chi^{2}[1549]=2399.43, p<0.01$; RMSEA $=0.059$ (90 \% CI: 0.055 $0.064)$; CFI $=.82$. Consc. $=$ Conscientiousness. The indirect relationships from conscientiousness via self-efficacy to academic performance (standardized effect $=.20, p<.001$ ) and military performance (standardized effect $=.30, p<.001$ ) were statistically significant. To simplify the graphical presentation, the additional path coefficients between the control variables and outcomes are reported in Table 2.

Figure 1: Structural Equation Model 
Since the results also revealed positive and significant direct relationships between conscientiousness at $\mathrm{T}_{1}$ and academic performance $(\gamma=.24, p$ $<.001)$ and military performance $(\gamma=.20, p<.001)$ at $\mathrm{T}_{3}$ the mediation is classified as "partial" (Baron \& Kenny, 1986) or as "complementary mediation" (Zhao, et al. 2010, p. 199). Accordingly, our hypotheses were partially supported as the results showed that self-efficacy partially mediated the relationship between conscientiousness and both academic and military performance (see Figure 1 and Table 2). Finally, we note that military performance in our study had weak negative relationships with extraversion $(\gamma=-.01, p<.001)$, emotional stability $(\gamma=-.07, p<.001)$, and openness to experience $(\gamma=-.11, p<.001)$, whereas academic performance had weak negative relationships with agreeableness $(\gamma=-.12, p<.001)$ and emotional stability $(\gamma=-.10, p<.001)$.

Table 2. Structural Equation Model for Predicting Academic and Military Performance

\begin{tabular}{|c|c|c|c|c|c|}
\hline \multirow[b]{2}{*}{ Control variables } & \multirow{2}{*}{$\begin{array}{c}\text { Selfefficacy } \\
\text { Direct }\end{array}$} & \multicolumn{2}{|c|}{ Academic Performance } & \multicolumn{2}{|c|}{ Military Performance } \\
\hline & & Direct & Indirect & Direct & Indirect \\
\hline Dummy 1 war college & -.01 & $.08 * * *$ & & $.09^{*}$ & \\
\hline Dummy 2 war college & -.05 & $.29 * * *$ & & $.26 * * *$ & \\
\hline Age & -.03 & .08 & & .09 & \\
\hline Sex & $-.16^{*}$ & -.21 & & -.05 & \\
\hline Civil education & $-.09 * * *$ & -.02 & & .04 & \\
\hline \multicolumn{6}{|l|}{ Predictor variables } \\
\hline Conscientiousness & $.50 * * *$ & $.24 * * *$ & $.20 * * *$ & $.20 * * *$ & $.30 * * *$ \\
\hline Agreeableness & $.10^{* * *}$ & $-.12 * * *$ & & -.06 & \\
\hline Extraversion & $.13 * * *$ & .00 & & $-.01 * * *$ & \\
\hline Emotional stability & -.04 & $-.10 * * *$ & & $-.07 * * *$ & \\
\hline Openness to experience & -.01 & -.05 & & $-.11 * * *$ & \\
\hline \multicolumn{6}{|l|}{ Mediator } \\
\hline Self-Efficacy & & $.41 * * *$ & & $.60 * * *$ & \\
\hline$R^{2}$ & .33 & .42 & & .51 & \\
\hline
\end{tabular}




\section{Discussion}

The present study examined the relationships between personality traits, selfefficacy and academic and military performance. SEM analyses showed that self-efficacy partially mediated the relationship between conscientiousness and academic performance as well as that of conscientiousness and military performance. Our findings, therefore, suggest that the relationship between conscientiousness and performance may be partially explained by selfefficacy. Accordingly, the results support the assumption that individuals who believe in their own capacity transform such basic dispositions into behaviour (Caprara et al., 2011; Martocchio \& Judge, 1997). Self-efficacy may thus be seen as a contributor to the development and regulation of behaviours that may be characterized as personality traits (Bandura, 2012). Accordingly, self-efficacy may guide inherent facets of conscientiousness (Giunta et al., 2013), both in preparing for a given task and in performing the task at hand. A plausible explanation for this may be found in the idea that increased interest, persistence and motivation, all of which come with higher levels of self-efficacy (Dinther et al., 2011), build upon the basic facets of an individual's conscientiousness; e.g., being methodical and disciplined, striving for achievement (McCrae \& Costa, 1999) and pushing for a higher level of performance.

In summary, our findings contribute to emerging studies that integrate trait theory and social cognitive theory. First, the results from our study show how this mediation mechanism applies to military performance in addition to recent studies that have demonstrated the correlations to academic (Caprara et al., 2011; Giunta et al., 2013) and work performance (Brown, Lent, Telander, \& Tramayne, 2011; Burns \& Christiansen, 2011). Second, the results show how the mediation model is simultaneously valid for both academic and military performance. The authors are not aware of any previous studies that have concurrently demonstrated such validity for the applied model. Consequently, the present study clarifies and supplements existing research by uncovering "when" and/or "for whom" this mediation model is likely to be manifested (Whetten, 1989).

These findings may have implications for predicting and enhancing academic and military performance. Personality tests are currently in use and 
under development in the Armed Forces in Norway as well as in Australia (McCormack \& Mellor, 2002) and France (Congard, Antoine, \& Gilles, 2012) and USA (Chappelle, Novy, Sowin, \& Thompson, 2010) among other places. Our study suggests that self-efficacy has a mediating effect on performance, which may explain why individuals with a high conscientiousness score perform well. This indicates that personality tests should be viewed from a broader perspective when military organisations use such tests as predictors of future academic and military performance. Military school instructors may use this as an argument to develop and adjust their educational programmes by focusing on ways to enhance students' selfefficacy and, as a result, their performance. In particular, educational programmes based on social cognitive theory have proven successful (Dinther et al., 2011).

This study exhibits important strengths and potential limitations that must be considered when interpreting the results. First, we used academic grades and instructors' evaluations from institutional records as a means of measuring performance, as objective indicators are considered to be more reliable, valid, and less biased than self-reports on performance (Viswesvaran, 2001). However, the use of self-reported data for both the Big Five personality traits and self-efficacy are susceptible to common method bias and social desirability (Podsakoff, MacKenzie, \& Podsakoff, 2003). In order to reduce this potential effect, respondents were clearly informed of the fact that data would only be used for research purposes. Second, we used different time intervals to measure personality traits, self-efficacy beliefs and performance in order to reduce common method variance by employing a time lag and obtaining measures from varied sources (Podsakoff et al., 2003). Because the most effective way of creating efficacy is through mastery experience (Bandura 1994), we chose to measure self-efficacy at T2 when the cadets have already gained some experience from taking exams and being evaluated, based on the assumption that self-efficacy would be more accurate at this time than at previous time points. To strengthen the measurement of selfefficacy, we used a scale that closely corresponded to the actual task (Pajares, 1996) rather than a single all-purpose measure (Bandura, 2012). Finally, the small sample size and moderate response rate used in this study may limit the generalizability of the results. However, the sample size should be 
sufficient to detect medium to large effects (Cohen, 1992). Moderate response rates are not unusual as indicated by a meta-analysis of survey studies resulting in a mean response rate of $49.6 \%$ (Horn, Green, \& Martinussen, 2009). We cannot completely rule out that non-responders are different from responders, which may bias the findings. Studies examining non-participation in surveys also indicate that data collected with moderate response rates are relatively unbiased when it comes to estimating health related issues (Søgaard, Selmer, Bjertness, \& Thelle, 2004). In general, a bias in our study will most likely result in less variation in the variables which in turn will result in smaller correlations due to range restriction (Hunter \& Schmidt, 2003), and thus represent a conservative bias in our analyses. Still, we suggest that this mediating model should be further investigated among larger samples.

In conclusion, our study extends the understanding of the relationships between conscientiousness and academic and military performance. This is useful in developing and understanding military personnel testing and in further augmenting military education and training. For future research, these results should be more closely investigated in relation to various cultures and different types of performance, in addition to including control groups in the analysis.

\section{References}

Bandura, A. (1994). Self-Efficacy. In V. S. Ramachaudran (Ed.), Encyclopedia of human behavior (Vol. 4, pp. 71-78). New York: Academic Press.

Bandura, A. (1997). Self-efficacy: The exercise of control. New York: Freeman.

Bandura, A. (1999). Social Cognitive Theory of Personality. In L. A. Pervin \& O. P. John (Eds.), Handbook of Personality. Theory and Research (2 ed., pp. 154-196). New York The Guilford Press.

Bandura, A. (2012). On the Functional Properties of Perceived Self-Efficacy Revisited. Journal of Management, 38(9), 9-44.

Bandura, A., \& Locke, E. A. (2003). Negative Self-Efficacy and Goal Effects Revisited. Journal of Applied Psychology, 88(1), 87-99. doi: 10.1037/00219010.88.1.87

Baron, R. M., \& Kenny, D. A. (1986). The Moderator - Mediator Variable Distinction in Social Psychological Research: Conceptual, Strategic, and Statistical Considerations Journal of Personality and Social Psychology, 51(6), 1173-1182. 
Barrick, M. R., \& Mount, M. K. (1991). The Big Five personality dimensions and job performance: a meta-analysis. Personel psychology, 44, 1-26.

Barrick, M. R., Mount, M. K., \& Judge, T. A. (2001). Personality and Performance at the Beginning of the New Millennium: What Do We Know and Where Do We Go Next. International Journal of Selection and Assessment, 9 (1/2), 9-30.

Brown, S. D., Lent, R. W., Telander, K., \& Tramayne, S. (2011). Social cognitive career theory, conscientiousness, and work performance: A meta-analytic path analyses. Journal of Vocational Behavior, 79, 81-90. doi: 10.1016/j.jvb.2010.11.009

Buch, R., Säfvenbom, R., \& Boe, O. (2015). The relationships between academic self-efficacy, intrinsic motivation, and perceived competence. Journal of Military Studies, 6(1), 1-17.

Burns, G. N., \& Christiansen, N. D. (2011). Self-efficacy in the Workplace: Linking personality to domain-specific efficacy beliefs. International Journal of Selection and Assessment, 19 (4. December 2011).

Caprara, Barbaranelli, C., Borgogni, L., \& Perugini, M. (1993). The "Big Five Questionnaire": a new questionnaire to assess the five-factor model. Personality and Individual Differences, 15, 281-288.

Caprara, Vecchione, M., Alessandri, G., Gerbino, M., \& Barbaranelli, G. (2011). The contribution of personality traits and self-efficacy beliefs to academic achievement: a longitudinal study. British Journal of Educational Psychology, 81, 78-96. doi: 10.1348/2044-8279.002004

Chappelle, W., Novy, P. L., Sowin, T. W., \& Thompson, W. T. (2010). NEO PIR Normative Personality Data That Distinguish U.S. Air Force Female Pilots. Military Psychology, 22, 158-175.

Cohen, J. (1992). A Power Primer. Psychological Bulletin, 112(1), 155-159.

Congard, A., Antoine, P., \& Gilles, P.-Y. (2012). Assessing the strctural and Psychometric Properties of a New Personality Measure for Use With Military Personel in the French Armed Forces. Military Psychology, 24, 284307. doi: 10.1080/08995605.2012.678242

Dinther, M. v., Dochy, F., \& Segers, M. (2011). Factors affecting students selfefficacy in higher education. Educational Research Review, 6, 95-108. doi: 10.1016/j.edurev.2010.10.003

Engvik, H., \& Føllesdal, H. (2005). The Big Five Inventory in Norwegian. Journal of the Norwegian Psychological Association, 42, 129-130.

Feyter, T. D., Caers, R., Vigna, C., \& Berings, D. (2012). Unraveling the impact of Big Five personality traits on academic performance: The moderating and mediating effects of self-efficacy and academic motivation. Learning and individual Differences, 22, 439-448. doi: 10.1016/j.lindif.2012.03.013 
Flora, D. B., \& Curran, P. J. (2004). An empirical evaluation of alternative methods of estimation for confirmatory factor analysis with ordinal data Psychological Methods, 9(4), 466-491.

Fritz, M. S., \& MacKinnon, D. P. (2007). Required sample size to detect the mediated effect. Psychological Science, 18, 233-239.

Giunta, L. D., Alessandri, G., Gerbino, M., Kanacri, P. L., Zuffiano, A., \& Caprara, G. V. (2013). The determinants of scholastic achievement: The contribution of personality traits, self-esteem, and academic self-efficacy. Learning and individual Differences, 27, 102-108. doi: 10.1016/j.lindif.2013.07.006

Hair, J. F., Black, W. C., Babin, B. J., Anderson, R. E., \& Tatham, R. L. (2005). Multivariate data analysis (6th ed.) Upper Saddle River, NJ: Prentice Hall.

Horn, P. S. V., Green, K. E., \& Martinussen, M. (2009). Survey Response Rates and Survey Administration in Counseling and Clinical Psychology: A MetaAnalysis. Educational and Psychological Measurement, 69(3), 389-403. doi: $10.1177 / 0013164408324462$

Hu, L., \& Bentler, P. (1999). Cutoff criteria for fit indexes in covariance structure analysis: Conventional criteria versus new alternatives. Structural Equation Modeling, 6(1), 1-55.

Hunter, J. E., \& Schmidt, F. L. (2003). Methods of meta-analysis: Correcting error and bias in research findings Beverly Hills, CA: Sage.

Johansen, R. B., Laberg, J. C., \& Martinussen, M. (2013). Military Identity as Predictor of Perceived Military Competence and Skills Armed Forces \& Society.

John, O. P., \& Srivastava, S. (1999). The Big-Five Trait Taxonomy: History, Measurement, and Theoretical Perspectives Handbook of personality: Theory and research (2nd ed.). New York: Guilford press.

Judge, T. A., \& Ilies, R. (2002). Relationship of Personality to Peformance Motivation. Journal of Applied Psychology, 87(4), 797-807. doi: 10.1037//0021-9010.87.4.793

Judge, T. A., Ilies, R., Bono, J. E., \& Gerhardt, M. w. (2002). Personality and Leadership: A Qualitative and Quantitative Review. Journal of Applied Psychology, 87(4), 765-780. doi: 10.1037//0021-9010.87.4.765

Judge, T. A., Jackson, C. L., Shaw, J. C., \& Rich, B. A. S. a. B. L. (2007). SelfEfficacy and Work-Related Performance: The Intregral Role of Individual Differences. Journal of Applied Psychology, 92(1), 107-127. doi: 10.1037/0021-9010.92.1.107

Jöreskog, K. G. (2005). Structural Equation Modeling with Ordinal Variables using LISREL. Technical documents., from http://www.ssicentral.com/lisrel/techdocs/ordinal.pdf

Kenny, D. A., \& McCoach, D. B. (2003). Effect of the Number of Variables on Measures of Fit in Structural Equation Modeling. Structural Equation 
Modeling: A Multidisciplinary Journal, 10(3), 333-351. doi: 10.1207/S15328007SEM1003 1

Kuvaas, B., Buch, R., \& Dysvik, A. (2014). Performance Management:

Perceiving Goals as Invariable and Implications for Perceived Job Autonomy and Work Performance. . Human Resource Management, n/a(n/a). doi: $10.1002 / \mathrm{hrm} .21680$

Martin, J. H., Montgomery, R. L., \& Saphian, D. (2006). Personality, achievement test scores and high school percentile as predictors of academic performance across four years of coursework. Journal of Research in Personality, 40, 424-431.

Martocchio, J., \& Judge, T. A. (1997). Relationship between conscientiousness and learning in employee training: Mediating influences on self-deception and self-efficacy. Journal of Applied Psychology, 82(764-773).

McCormack, L., \& Mellor, D. (2002). The Role of Personality in Leadership: An application of the Fice-Factor Model in the Australian Military. Military Psychology, 14(3), 179-197.

McCrae, R. R., \& Costa, P. T. (1986). Personality stability and its implications for clinical psychology. ClinicalPsychology Review, 6, 407-423.

McCrae, R. R., \& Costa, P. T. (1999). A Five-Factor Theory of Personality. In L. A. Pervin \& O. P. John (Eds.), Handbook of Personality (2 ed.). New York: The Guilford press.

Mischel, W., \& Shoda, Y. (1998). Reconciling prcessing dynamics and personality dispositions. Annual Review of Psychology, 49, 229-258.

Multon, K. D., Brown, S. D., \& Lent, R. W. (1991). Relation of self-efficacy beliefs to aademic outcomes: A meta-analytic investigation. Journal of Counseling Psychology, 38, 30-38.

Muthén, B. O., du Toit, S. H. C., \& Spisic, D. (1997). Robust inference using weighted least squares and quadratic estimating equations in latent variable modeling with categorical and continuous outcomes. Conditionallly accepted for publication in Psychometrika.

Pajares, F. (1996). Self-Efficacy Beliefs in Academic Settings. Review of Educational Research, 66(4), 543-578.

Podsakoff, P. M., MacKenzie, S. B., \& Podsakoff, N. P. (2003). Common Method Biases in Behavioral research: A Critical Review of the Literature and Recommended Remedies. Journal of Applied Psychology, 88(5), 879903. doi: 10.1037/0021-9010.88.5.879

Poropat, A. E. (2009). A meta-Analysis of the Five-Factor Model of Personality and Academic Performance. Psychological Bulletin, 135(2), 322-338. doi: $10.1037 / \mathrm{a} 0014996$

Richardson, M., Abraham, C., \& Bond, R. (2012). Psychological Correlates of University Students' Performance: A systematic Review and Meta-Analyses. Psychological Bulletin, 138(2), 353-387. doi: 10.1037/a0026838 
Robbins, S. B., Lauver, K., Le, H., Davis, D., Langley, R., \& Carlstrøm, A. (2004). Do psycholsocial and study skils factors predict college outcomes? A meta analysis Psychological Bulletin, 130, 261-288. doi: 10.1037/00332909.130.2.261

Salgado, J. F. (1998). Big Five Personality Dimensions and Job Performance in Army and Civil Occupations: A European Perspective. Human Performance, 11(2/3), 271-288.

Sellman, W. S., Born, D. H., Stricland, W. J., \& Ross, J. J. (2010). Selection and Classification in the U.S. Military. In J. L. Farr \& N. T. Tippins (Eds.), Employee Selection (pp. 679-699). New York Routledge.

Shamir, E. (2011). Transforming Command. The Pursuit of Mission Command in the U.S, British and Israeli Armies. Stanford, California: Stanford University Press.

Stajkovic, A. D., \& Luthans, F. (1998). Self-efficacy and Work-Related Performance: A Meta-analysis. Psychological Bulletin, 124(2), 240-261.

Søgaard, A., Selmer, R., Bjertness, E., \& Thelle, D. (2004). The Oslo health study: the impact of self selection in a large, population-based survey. International Journal for equity in Health, 2004(3:3), Retrieved Aug 7, 2015 from http://www.equityhealthj.com/content/2013/2011/2013. doi: 10.1186/1475-9276-3-3

Tabak, F., Nguyen, N., Basuray, T., \& Darrow, W. (2009). Exploring the impact of personality on performance: how time-on-task moderates the mediation by self-efficacy. Personality and Individual Differences, 47, 823-828. doi: 10.1016/j.paid.2009.06.027

Tett, R. P., Jackson, D. N., \& Rothstein, M. (1991). Personality measures as predictors of job performance: a meta-analytic review. Personel psychology, 1991(44), 703-742.

Viswesvaran, C. (2001). Assessment of individual job performance: A review of the past century and a look ahead. In N. Anderson, D. S. Ones, H. K. Sinangil, \& C. Viswesvaran (Eds.), Handbook of industrial, workd and organizational psychology: Vol. 1. Personnel psychology (pp. 110-126). London: Sage.

Whetten, D. A. (1989). What Constitutes a Theoretical Contribution? The Academy of Management Review, 14(4), 490-495. doi: 10.2307/258554

Zhao, X., Lynch, J. G., \& Chen, Q. (2010). Reconsidering Baron and Kenny: Myths and truths about mediation analysis. Journal of Consumer Research, 37, 197-206. 